\title{
EXPRESSIVISM ABOUT DELUSION ATTRIBUTION
}

\author{
Sam Wilkinson \\ University of Exeter \\ Original scientific article - Received: 4/9/2020 Accepted: 22/9/2020
}

\begin{abstract}
In this paper, I will present and advocate a view about what we are doing when we attribute delusion, namely, say that someone is delusional. It is an "expressivist" view, roughly analogous to expressivism in meta-ethics. Just as meta-ethical expressivism accounts for certain key features of moral discourse, so does this expressivism account for certain key features of delusion attribution. And just as meta-ethical expressivism undermines factualism about moral properties, so does this expressivism, if correct, show that certain attempts to objectively define delusion are misguided. I proceed as follows. I start by examining different attempts at defining delusion, separating broadly psychiatric attempts from epistemic ones. I then present a change of approach, according to which we question whether the term "delusion" is in the business of (merely) describing reality. I then support this proposal, first, by borrowing standard lines of argument from meta-ethics (including ontological reluctance, intrinsic motivation, and deep disagreement) but also, by inference to the best explanation of some the features we see when we try to theorise about delusion (namely that it is hard to define, and that our delusion attributions are elicited by a plurality of norms).
\end{abstract}

Keywords: Delusion attribution; expressivism; non-factualism; epistemic norms; folk epistemology 


\section{Defining Delusion}

There is an ambiguity in the question "What is delusion?" In particular, is this question paradigmatic or parametric? By this I mean: is the question asking us to provide paradigmatic examples of delusion? In other words, is it asking us to point to or describe the sorts of things that get called delusions? Or is it asking us to provide parameters that strictly categorize any phenomena, even hypothetical phenomena, as delusional or not? The standard way to think of such parameters is in terms of necessary and sufficient conditions, free from counter-examples. These can then function as a sorting algorithm. You input the target phenomenon and it tells you whether it is a delusion or not. This is what is often meant by a definition, at least in philosophy.

The paradigmatic answer is often thought to be unsatisfying since it invites the follow-up question: "Yes, but why are these paradigmatic instances of delusions?" This invites attempts to define delusion, which I will broadly present now. I will present psychiatric approaches, then epistemic approaches, and then motivate a total change of tactic.

\subsection{Psychiatric Approaches}

The prominent psychiatrist Tony David speaks of the "impossibility of defining delusions" (1999) in a paper of that title:

Most attempted definitions begin with "false belief", and this is swiftly amended to an unfounded belief to counter the circumstance where a person's belief turns out to be true. Then caveats accumulate concerning the person's culture and whether the beliefs are shared. Religious beliefs begin to cause problems here and religious delusions begin to create major conflicts $[\ldots]$. The beleaguered psychopathologist then falls back on the "quality" of the belief - the strength of the conviction in the face of contradictory evidence, the "incorrigibility", the personal commitment, etc. Here, the irrationality seen in "normal" reasoning undermines the specificity of these characteristics for delusions [...] as does the variable conviction and fluctuating insight seen in patients with chronic psychoses who everyone agrees are deluded [...]. Finally we have the add-ons: the distress caused by the belief, its preoccupying quality, and its maladaptiveness generally, again, sometimes equally applicable to other beliefs held by non-psychotic fanatics of one sort or another. In the end we are left with a shambles. (David 1999, 17-18) 
This lament (and it surely is a lament with strong negatively laden terms like "beleaguered" and "shambles") is revealing of two interesting things. First, when theorists talk of "defining" delusion, they seem to want a clear presentation of necessary and sufficient conditions. This is seen by the fact that counter-examples are seen to be damaging to such a definition. What provide counter-examples to any definition (e.g. the DSM definition) are cases where the delusional status (and indeed pathological status) has already been recognised. That's why they are counter-examples! This means, though, that any definition isn't guiding our judgements about delusional status. We've already made these judgements intuitively.

The second thing is that David seems to be assuming that delusions must, as a matter of conceptual necessity, be pathological. This can be seen from the fact that he takes irrationality in the "normal", healthy, population to undermine a definition that might be based only on irrationality, rather than allowing that delusions in healthy people might not be a contradiction in terms.

Contrast this with, for example, what philosopher Kengo Miyazono (2015) writes in a paper explaining what it is that makes some delusions pathological: "I do not assume that all delusional beliefs are pathological [...] I only discuss typical delusional beliefs that are pathological" (Miyazono 2015, 561, fn.1). Similarly, Valentina Petrolini (2017), also a philosopher, presents a fascinating account of what makes delusions pathological in terms of dysfunctional relevance detection. But, like Miyazono, there is no assumption that delusions must by definition be pathological, only that, when they are, and the canonical ones are, this explains why. And again, in a similar vein, Lancellotta and Bortolotti (this issue) examine the implications that different accounts (different versions of two-factor accounts, to be precise) of the Capgras delusion have for whether the delusion should be counted as pathological. This enterprise would only make sense on the (in my view very sensible) assumption that delusions aren't pathological by definition.

This contrast reveals two ways of approaching delusion. First, you can think of it as a diagnostically important psychiatric concept, a Jaspers-style "marker of madness", in light of which non-pathological delusion is indeed a contradiction. Second, and alternatively, you can think of it as a concept that has to be carefully defined in terms of epistemology, or, at least, not centrally as a medical phenomenon, but as a (more abstract, perhaps) mental state that is subject to various normative evaluations, most notably, epistemic ones. 
One can easily understand why clinicians will tend to see delusions as pathological by conceptual necessity: delusions that are (deemed) pathological are the ones that are likely to come to their attention. But suppose that, instead of thinking of delusion as necessarily pathological, we thought of the relationship between mental illness and delusion as less direct. On such a view, the sorts of things that we call delusions tend to be pathological, but they aren't by conceptual necessity. Indeed, even if it were in practice impossible to have a delusion that wasn't pathological, it wouldn't be a contradiction in terms. For Miyazono (2015), for example, delusions might well be caused by, and indicative of, pathology (construed as harmful dysfunction (Wakefield 1992)), but aren't conceptually tied to this. We will return to the relationship between delusion and pathology later.

\subsection{Epistemic Approaches}

Whatever we take delusion to be, one thing that seems fairly obvious is that they (and the subjects who have them) are breaking norms, and, in particular, epistemic norms. As David puts it, at a minimum, they seem, most centrally, to be "unfounded belief". Echoing this, Max Coltheart (2007, 1043) writes: "couldn't a true belief be a delusion, as long as the believer had no good reason for holding the belief?" Indeed, the DSM 5 (American Psychiatric Association 2013) has picked up on this by dropping the falsehood requirement. ${ }^{1}$

This way of putting things introduces the notion of reasons, and epistemic rationality. ${ }^{2}$ Unfounded beliefs are epistemically irrational, but epistemic rationality is a broader notion that encompasses, but is not exhausted by, evidentiary grounding (i.e. the "founding" of belief). Epistemic rationality is to be contrasted with practical rationality. Rationality in general can be thought of in terms of the attainment of certain aims. Practically rational

\footnotetext{
${ }^{1}$ Many thanks to Valentina Petrolini for pointing this out to me.

${ }^{2}$ In the context of a different debate, surrounding the question of whether delusions count as beliefs, Lisa Bortolotti (2009) distinguishes three kinds of rationality: procedural, epistemic, and agential rationality. Procedural rationality is about how a belief relates to other mental states, epistemic rationality about how it relates to evidence, and agential rationality about how it relates to action. The assessed claim is that these forms of irrationality, present in delusions, prevent delusions from being counted as beliefs. Bortolotti convincingly argues that these forms of irrationality are present in non-delusional beliefs too, and so if we were to deny belief-status for delusions, we'd have to do it for many other things that we count as beliefs. Note that this pertains to belief-status, rather than delusion-status. But since Bortolotti is keen to show that these forms of irrationality are present in non-delusional belief, she will agree with me that they can't function as fully definitive markers of delusion.
} 
action is action that maximizes our chances of fulfilling our own aims ("motives", "desires"). So an irrational action is an action that does a bad job of fulfilling these. For example, a reluctant addict's behaviour (e.g. someone who wants to stop smoking but can't) is perhaps a prime example of practical irrationality. So what is an epistemically rational belief? Whether we can aim at anything while believing is controversial (Williams 1970), however, the idea that belief itself aims at truth is seen by many as highly plausible (Velleman 2000; Wedgewood 2002). There are many characterisations of epistemic rationality, but a simple one that suits our purposes is belief-formation that has maximized its chances of achieving its goal, namely, truth. So, what is actually involved in epistemic rationality, such that it is (as we say) truth-conducive?

A combination of things might count. As we've said, using adequate evidence in the formation of a belief, giving due weight to evidence that might cause you to revise your belief, not allowing motivational influences to derail your tracking of the truth (i.e. wishful thinking), having a certain degree of consistency among the beliefs that you hold, not compartmentalising information that is inconsistent, and so on. Here is the core question we come to: Can delusion be defined in terms of epistemic irrationality, thus construed?

\subsubsection{Not Sufficient: Non-Delusional Irrationality}

There are two issues that it is important to separate. One is a relatively minor issue: where do we draw the line? I call this issue "relatively minor", because it allows that irrationality could in principle do the job, but there's a challenge about where we place the threshold. Of course, one might think that a valuable revision to our practices is to think of delusion as being on a gradation, rather than something that is binary. On such a view, people aren't simply delusional or not, but are rather more or less delusional. The threshold at which someone tips from non-delusional irrationality to delusional levels of irrationality is arbitrary, or at best drawn on the basis of non-epistemic considerations, such as how well the person "functions", whether the delusion causes suffering, whether other symptoms are present, and so on. This is perhaps an attractive position.

The more damaging issue undermines even this more relaxed gradualism. What the gradualism is minimally committed to is some kind of correlation between irrationality and this gradual "delusionality". In other words, the more irrational you are, the more delusional you are. The worry is that this correlation may not hold. Stated plainly, Person A might be more epistemically irrational than Person B, but in fact turn out to be less delusional. 
Consider, for example (from Nozick 1993, cited in Murphy 2012), a mother whose son has been convicted of murder. We can understand that she will be highly resistant to evidence that suggests that he is guilty. We will not, however (I would suggest) be tempted to call her delusional. (rather, this would be classified more naturally as self-deception (see Mele 2006)) People in these situations are believing in ways that are epistemically deeply irrational (they are far from being truth-conducive), but they are intuitively not delusional. Why is this? I would suggest that it is because we can recognise their motivations, and we can recognise the influences that these can have on belief-formation and maintenance. This means that we find their epistemic irrationality unsurprising and understandable. This is just part and parcel of our folk models of other human beings. We might even recognise (implicitly or explicitly) that in similar circumstances we would do similarly. We might even be repulsed by a mother who calmly and dispassionately evaluated evidence pertaining to her son's guilt accurately. We model other human beings (and ourselves) as understandably biased and emotional creatures. Of course, there is an extreme level of evidence-resistance at which a threshold could be crossed and we might be tempted to call the mother in our example delusional. But, crucially, the threshold is significantly higher as a result of our folk understanding of motivational influences on belief. This shows that degree of epistemic rationality alone cannot determine delusional status.

This, I would suggest, points towards a major change of approach. However, before moving on to this new approach, let's look at the other reason why delusion cannot be defined in terms of epistemic rationality, namely, that it might not even be necessary, let alone sufficient.

\subsubsection{Not Necessary: Rational Delusion?}

Might there be cases of delusion that don't involve any irrationality in the sense we have just sketched? There are two very different kinds of grounds one might have for claiming this. One is on the basis of already existing (and in principle empirically testable) theories about how certain cases of delusion come about. The other is a conceptual argument that can be supported with thought experiments.

With advancements in cognitive neuropsychiatry we have moved beyond the observable behaviour of delusional individuals to some understanding of what might underpin the formation of these delusions. In particular, there has been increasing support for the view that these delusions are in fact formed on the basis of some kind of anomaly at the level of experiential input. To put it in more intuitive terms, if you or I were to experience what these patients experience, then we too would form the 
delusions that they form. As Brendan Maher presciently put it, at a time before neuropsychological theories of delusions were available, "The delusional belief is not being held "in the face of evidence strong enough to destroy it", but is being held because evidence is strong enough to support it" (Maher 1974, 99). The point is that we can think of (at least some) delusions as arising from correct use of very bizarre input (what Maher calls "evidence"), instead of from a misuse of normal input.

As we are about to see, most philosophers and neuropsychologists in the field agree that many paradigm cases of delusion have at least some experiential grounds. The main source of contention is whether this experiential anomaly is strong enough (carries enough epistemic weight) to explain why the delusion is maintained for so long, or whether we need to postulate a bias of some kind (Langdon and Colheart 2000, for example, think that we do). In the latter case, the delusional patient would be charged with epistemic irrationality.

However, whether or not there actually are biases at work is an empirical question, and our aim is to ascertain, regardless of whether certain realworld delusional patients are epistemically irrational or not, whether, if there were people who believed these bizarre things on the basis of fully adequate private grounds, and hence are plausibly epistemically rational (or at least as epistemically rational as "normal" people), we would still rightly consider them to be delusional. To put it another way, if Maher's theory happened to be correct (regardless of whether it actually is or not) would these patients still count as delusional?

Jennifer Radden (2010) calls these, rather aptly, "perceptual delusions". Her view is that, as "reasonable inferences from misleading perceptual experiences, "perceptual delusions" are not epistemic lapses of the sort by which delusional states are identified" (2010, 28, emphasis added). This amounts to us retrospectively revising our delusion attributions in light of a stipulation that delusions are tied to epistemic irrationality, and the discovery that a significant proportion of delusional states aren't after all irrational in the requisite way. In other words, it may turn out that some paradigmatic cases of delusion aren't delusional after all, since they aren't really irrational in the required way. This position is coherent, but such an overarching revision of what we deem to be a delusion needs to be thoroughly motivated, and I fail to really see such motivation. Are we really ready to say that a paradigmatic delusion like, for example, the Capgras delusion isn't really a delusion? Surely what matters is not the individual, experiential evidence that the person has, but how their beliefs 
and believing (assertions and behaviours) fit with our social epistemological landscape. ${ }^{3}$

So, in contrast to Radden, I am tempted to say: "Yes, these patients still count as delusional". This is for reasons related to the change of approach I am about to present. Notice that this is also in line with Maher's implicit view. It certainly wasn't his intention to show that these patients, who we previously had taken to be paradigm cases, were not, after all, "really" delusional. Rather, the question he is answering is: granting that they are delusional, how can we explain their delusional state?

\subsubsection{Murphy's Clue: An Alternative Approach}

In a 2013 paper, Dominic Murphy doesn't quite go as far as making the proposal that I am about to, but offers an important clue that leads to it. $\mathrm{He}$ writes:

A delusion is a false belief, just as knowledge is true belief, but, as with knowledge, philosophers do not rest there. Knowledge is true belief plus something else. So too, philosophers try to find that extra property of the false belief that converts it from a mere false belief into a delusion. (Murphy 2013, 115, emphasis added)

Putting aside the issue of delusions being accidentally true (since though truth is a way for a belief to be good, there are other ways in which it can be bad) this is to my mind a very important observation. It reminds me of something that Hartry Field wrote 15 years earlier in a wonderful paper presenting Epistemological Nonfactualism. He writes:

Debates in epistemology [...] often sound as if what is under discussion is the presence or absence of some mysterious justificatory fluid [...]. Admittedly, one might reject the justificatory fluid picture and still regard epistemological debates as fully factual: one might say that the factual question is about which [...] policies have such properties as reliability.

\footnotetext{
${ }^{3}$ In a very recent paper that is highly amenable to what I am saying here, Miyazono and Salice (2020) argue for the view that delusion should be seen through the lens of social epistemology, and, in particular, in terms of its relationship to what they call "social sources of evidence" rather than "individualistic sources of evidence". Adopting a similar tactic, Cardella (this issue) examines the fascinating hypothesis that delusions do not centrally involve irrationality (construed individualistically), but rather deficits in social cognition or common sense. On the contrary, she argues, delusional individuals are by some measures more rational and better at reasoning logically than non-delusional individuals.
} 
But this "naturalization move" obscures the fact that we are interested in which policies have factual properties like reliability only insofar as this bears on the practical question of which policies to employ. It is the practical question that is primary, and it is not itself a factual question. (Field 1998, 7)

This criticism, levelled at epistemology in general, I think could equally be levelled at attempts to define delusion, too. And Field's epistemological nonfactualism has inspired me to reflect on a similar position when thinking about delusion. To simplify somewhat, what Field is arguing is that, (i) you are going to struggle to find a descriptive, factual recipe that picks out all and only the things that count as epistemically good (e.g. "knowledge"), but even if you could (but you can't) it misses the fact that the whole point of the epistemically good is about the practical question about what epistemic policies to employ. And the question "What policy should I employ?" just isn't a factual question. Similarly, for delusion, the question "What beliefs and ways of believing should I avoid?" also isn't a factual question.

\section{The Expressivist Proposal}

Nonfactualism and expressivism are closely associated, although they do not strictly entail one another. Nonfactualism is an ontological position, a claim about reality, about the world, concerning whether there are facts corresponding to certain domains of discourse. Expressivism, in contrast, is a claim about the nature of the discourse itself. It is possible to be a nonfactualist, but not an expressivist about a given domain (e.g. an error theorist or fictionalist), and conversely to be an expressivist, but a factualist (e.g. a quasi-realist). However, in the absence of certain facts, a popular way of accounting for a particular domain of discourse is to be an expressivist about that particular domain, namely, to claim that, although it looks like the domain is in the business of describing facts, it is actually doing something else (namely, "expressing" something in a sense that I will make clear shortly).

\subsection{What is Expressivism?}

Expressivism about a certain kind of discourse is a position concerning the meaning of that discourse, or, which perhaps (depending on one's views of language) comes to the same thing, what we are doing when we are engaged in that discourse. Expressivists tend not to be expressivists about all kinds of discourse, so, expressivists about ethics are making a claim about ethical discourse, and usually distinguish that from other domains of 
discourse, and, in particular, fact-stating discourse. "Grass is green" means what it does in virtue of the fact that it can be used to describe a fact, namely, the fact that grass is green. In terms of the psychological state of someone who uses that sentence, it is common to say that asserting sincerely (and without conceptual confusion) "Grass is green" is taken to express the belief that grass is green. Expressivists about ethical discourse who can agree that this picture is roughly correct, however will deny that it generalises to ethical discourse (see, e.g. Hare 1952). They will say that ethical sentences don't describe facts, and that the psychological states of those who sincerely assert ethical sentences, namely those that are expressed by their assertions, are not factual beliefs but something else with various proposals, including emotions (Ayer 1952), desire-like prescriptions (Hare 1952), attitudes of being for (or against) (Gibbard 1990; Schroeder 2008), impassioned beliefs (Ridge 2014), and so on.

An important step towards understanding expressivism is to understand this notion of "expression". What is expressed, in the sense relevant to understanding expressivism, is to be distinguished from what is said or articulated. Thus "Ouch!" is an expression of being in a state of pain, whereas the utterance "I am in pain" is an articulation of that state. Expressivism wants to think of moral claims as expressions in a way somewhat analogous to the way that "Ouch!" is an expression of pain. What a certain utterance expresses, in the relevant sense, is the mental state that it reveals that you have, not that it describes you as having. Note that fact-stating assertions express things too, but, unlike "Ouch!", they express in virtue of describing. "The cat is black" is an articulation that the cat is black, but, if sincerely asserted, is an expression of my belief that the cat is black; stipulating sincerity on my part, it reveals that I have that belief.

\subsection{Two Kinds of Evaluation and Evaluative Discourse}

When we say that people are delusional, we are evaluating them negatively. Everyone will agree with this. However, it is vitally important to distinguish two different kinds of evaluations. One we might call descriptive evaluations. What you do when you descriptively evaluate is you describe a benchmark, and say that the thing in question is attaining or failing to attain said benchmark. For example, you might be selecting a basketball team, and have the policy that only players over $6 \mathrm{ft} 2$ will be considered. There's a purely descriptive sense in which shorter players are deemed "inadequate". The assertion that "this player is too short" need only (indeed will only) express factual belief (e.g. the belief that this player is 6ft1). In philosophy these benchmarks are everywhere, and they are theoretically rich and informed. For example, theorists in philosophy of biology will provide conditions for biological proper function. Traditional 
epistemology ("naturalized" or otherwise), of the kind Field derides, does the same for knowledge. Don't let the theoretical sophistication at play hide the fact that, like the basketball team selection, these evaluations are fact stating, descriptive. They describe a certain state of affairs and are true if and only if that state of affairs obtains. To put it another way, they are often taken to be unproblematically reducible to non-evaluative facts. In a sense, they aren't really evaluations; they are descriptions.

Some evaluations contrast with descriptive evaluations in being what we might call deeply evaluative. These evaluations are not about picking out a benchmark and stating that the thing in question either attains of fails to attain that benchmark. They are claims we make when we are evaluating as opposed to describing. This is most simply unpacked in terms of being in evaluative rather than descriptive mental states. Typical candidates of such deep evaluations are moral evaluations (right and wrong, good and evil). An expressivist about delusion attribution would take the attribution of delusion to be an evaluation in this deep and irreducible sense. This does not mean that calling someone delusional is negatively evaluating them morally (in fact, it often has quite the opposite effect). Rather, what moral discourse and delusion attribution have in common is that they are both evaluative in a way that doesn't allow them to be analysed in factual, nonevaluative terms.

Expressivism takes the sincere claim "Murder is wrong" to express something other than a straightforward factual belief. ${ }^{4}$ The precise details of these are not what interest us now, but rather the view that there are kinds of claims, domains of discourse, that do not describe, that are not expressions of factual beliefs, but that do something else by expressing something else. This philosophical move, with regards to a certain kind of discourse, might be called the "basic expressivist move". One of the nicest general articulations of this move was made by Sellars (who was writing too early to have ever called himself an expressivist):

\footnotetext{
${ }^{4}$ At this point, a vital point of clarification is needed, related to this stipulation of sincerity. The "meaning" of the word, in the relevant sense, is preserved whether or not the speaker actually is in the relevant mental state. Even less is the meaning straightforwardly derived from the speaker's mental state. Language is a public and socially distributed affair. Rather, the meaning of the word, on the expressivists account, is derived from the mental state that the word has the function of expressing. There's nothing odd about this. It applies quite naturally to other uses of language. An assertion still does what it does, and means what it means, if I don't believe or otherwise endorse its content. But we understand what the assertion "The cat is black" means because its default function is to express the belief that the cat is black. Indeed, lying works precisely because it exploits this function.
} 
$[\mathrm{O}]$ nce the tautology 'The world is described by descriptive concepts' is freed from the idea that the business of all nonlogical concepts is to describe, the way is clear to an ungrudging recognition that many expressions which empiricists have relegated to second-class citizenship in discourse are not inferior, just different. (Sellars 1957, 282)

My central suggestion is that "delusion" is not (or at least not primarily) in the business of describing. But it is not thereby inferior, just different.

\subsection{Why be an Expressivist about Delusion Attribution?}

Many of the considerations that motivate expressivism about ethics apply to delusion. These are:

1. Ontological reluctance

2. Intrinsic pragmatism

3. Deep disagreement

I'll go through these quite quickly, in turn, since I think that what is really interesting lies beyond this.

What I'm calling "ontological reluctance" is sometimes called (in Mackie's rather dated terminology) the "argument from queerness", although I take it to be broader and more general. Some theorists are generally reluctant to posit a strange ("queer", namely, "of a very strange sort, utterly different from anything else in the universe" (Mackie 1977, 38)) realm of moral properties or facts. But more generally, regardless of what we are calling these things (properties, facts etc.) there can also be a general reluctance to engage in ontology in the classical sense (e.g. social ontology being exempt) at all, when we can account for the phenomenon in question without any mysteries outstanding. Within the context of this ontological reluctance, expressivists about ethical discourse feel a certain calm when they reflect on the fact that social creatures like ourselves will have sought to regulate behaviour in a pro-social way by expressing (revealing) to conspecifics their disapproval, and thereby motivating the community at large to reward and punish so as to secure adherence to social norms (morality, politeness etc.). Similarly, the argument would go, there are no sui generis delusion-pertaining (or indeed, knowledge-pertaining) facts or properties. Social creatures like us who communicate and try to live in groups, are going to give rough-and-ready seals of approval (thumbs up) to good epistemic states and practices, and give thumbs down to poor ones. The fact that the words "knowledge" and "delusion" emerged in English, and became roughly regimented, is just a distraction. 
This relates to the second consideration. Moral discourse is intrinsically motivating. There is a certain contradiction to sincerely claiming "Murder is wrong" while not thereby feeling motivated in certain ways, e.g. a ceteris paribus reluctance to murder, encourage others not to murder, etc. Similarly, delusion discourse seems intrinsically motivating: it would be inconsistent to regard someone as delusional, and yet have no inclination to refrain from taking what they are saying seriously, no inclination to not argue against them, and so on. Of course, these inclinations are multi-track and dispositional. You don't have to act in accordance with them, and they don't have to be exhaustively listed. The evaluative state is not simply the aggregate of these motivations, rather the motivations fall out of the evaluative state.

Finally, there is the consideration behind deep disagreement. In these instances, all of the facts pertaining to a particular case are agreed by two individuals, and yet there is still disagreement about where something is morally wrong. There is no further fact that can be learnt in order to bring the two disagreeing subjects in line with one another. Therefore, it is not a disagreement about facts, but about something else. Of course, on many very serious moral infringements (murder), unanimity is not hard to find, but for more contentious culturally specific "beliefs" (sex before marriage, homosexuality, abortion etc.) these deep disagreements are rife. A similar thing could be said for delusion. There are not only disagreements about what counts as good/bad, acceptable/unacceptable belief contents; there are also disagreements about what counts as good methods and procedures for forming beliefs. Murphy (2013) presents this example in a paper that very much follows the spirit, if not to the letter, of what I am saying here.

\begin{abstract}
Boyer, (2001, 69-70) reporting fieldwork done by Wendy James in the Sudan, discusses ebony trees that are believed to be a source of social information. The trees record conversations, and are privy to the plans of witches. You can learn what they know by burning an ebony twig, dipping it in water and reading the pattern of ashes in the water. A belief in cognitive interaction with ebony trees counts as culturally normal, and hence not delusional or otherwise suspect. (Murphy 2013, 22)
\end{abstract}

This final "delusional or otherwise suspect" is very much in keeping with the picture I'm presenting. To call something delusional is to express your folk-epistemic disapproval, to flag it as suspect. Aside from these theoretical considerations, there is a far more intuitive consideration one can appeal to: it just seems right. Just consider something you might overhear in public between two friends: "You're delusional if you think 
that Manchester United can qualify for the Champions League!" You'll grant me that this seems like an expressive rather than descriptive use of language. But is this a particularly exotic and non-standard use of the word? Is this making expressive use of a linguistic tool that is originally purely descriptive? Or is it a hyperbolic use of a linguistic tool that is already to some extent expressive? I would be tempted to say the latter. Just because the word "delusional" is being uttered calmly by someone in a white lab-coat holding a thick book, doesn't make it any less expressive in its semantics. (Recall that the speaker does not have to be in the emotional state canonically expressed by the word, any more than I have to believe every single descriptive assertion that I utter.)

\subsection{The Consequences of Expressivism about Delusion Attribution}

The consequences of expressivism serve to lend further support to it. In a sense, we can adopt expressivism as an inference to the best explanation, since some of its consequences align with what we already observe.

\subsubsection{Inability to Define is to be Expected}

The inability to define delusion is not only to be expected, but embraced. If delusion talk expresses (reveals) our reactive folk epistemological attitudes, then we would certainly not expect these attitudes to track consistent parametric properties that can be captured by necessary and sufficient conditions. These are not going to survive the scrutiny of counterexamples. But, again, where do the counterexamples come from in the first place? I'd say, our reactive folk epistemological attitudes. The definitions don't function to tell us what's delusional: we have a sense of that already. Similar things of course can be said of our sense of right and wrong. And, again, we would expect all sorts of things to interfere with any clear, factual, theoretically informed judgment of delusion. Culture, motivation, even the way in which the case is presented, may influence the extent to which someone deems a belief (or assertion) to be bad. This relates to the second consequence.

\subsubsection{Disjunctive Norm Pluralism}

There are many different ways in which a belief (and related phenomena, like inquiry, reasoning, etc.) can be good or bad. Two obvious ways are the process-independent dimension of truth and falsehood, and the processdependent dimension of rationality. Both of these contribute to the "badness" of the belief, and all that matters is that there is enough folkdetectable badness. It doesn't matter where it comes from. Take reverse Othello delusion. The belief content that the subject's wife is not cheating 
on him is a perfectly plausible content taken in isolation. It is true (one hopes) of hundreds of thousands of people around the world. What makes it delusional is the subject's baffling blindness in the face of counterevidence. On the other end of the spectrum, it matters little what evidence a delusional patient might cite for the claim "I am the left foot of God." We just don't see how that could possibly be true. There are likely many other epistemic norms that we detect (e.g. cognitive flexibility, relevance detection etc.) and they may all be involved in tipping the balance toward the (folk-epistemically) bad or good. Since it doesn't matter on what types of grounds the belief is deemed to be bad, we have what we might call disjunctive norm pluralism when it comes to something being delusional or not.

A related point concerns "understandability". Like we saw in the case of the mother in an understandable level of denial about her son's guilt, a sort of pluralistic criterion of understandability tracks our delusion attributions better than something like rationality. Interestingly, Jaspers is often quoted as saying that delusions are "un-understandable", and this is often interpreted as meaning that they cannot be theoretically understood. Whether or not this is the correct interpretation, there is an interpretation of this claim according to which it approximates an accurate claim. That is, if we think of all of the different folk-epistemic norms as constituting this rough criterion of "understandability", which is basically about whether somebody adheres to our predictive models of how humans should behave (i.e. they should be resistant to evidence that casts their loves ones in a very bad light, up to a certain point). Calling something delusional is to say: "Wow, this person is flying in the face of the models I use to make sense of people!"

\section{Delusion and Pathology Revisited}

We examined the idea that delusion and pathology should not be conceptually tied to one another. However, suppose that we are expressivists about delusion attribution. What does that say about the relationship between delusion and pathology? There are a number of options, depending on how we think of pathology.

One way to go is to think that, whereas delusion is a folk concept that is deeply evaluative, pathology is a theoretical notion (or at least should be (see Boorse 1975)). Then that theoretical notion is to be thought of in objective and fact-stating terms. This would grant total conceptual independence between delusion and pathology. It might turn out that many of the things that we deem to be delusional are the results of things that, 
according to this factual, theoretical notion, are also pathological. To take an imperfect, but still helpful, analogy: I might dislike the taste of tomatoes. A chemist might be able to isolate the exact compound in the tomato that arouses my dislike. The claim that tomatoes contain that compound is a factual claim, my assertion "tomatoes are yucky" is not (note, though, the claim that "SW dislikes tomatoes" is clearly factual just like claims about whether an individual attributes delusion is factual although the attribution itself is not).

A closely related view would have a hybrid approach to pathology, e.g. Wakefield's harmful dysfunction account, where the factual component of dysfunction is necessary but not sufficient: the value-laden notion of harm is needed in addition. This means, similarly, that some of the things that we deem to be delusional are pathological. Note that not only is this consistent with Miyazono's paper, his task is to use Wakefield to tell us why the things we deem to be delusions that are pathological count as pathological. He is, in a way that is very much in the spirit of what I am saying here, not interested in delineating the realm of the delusional.

Finally, we could be non-factualists about pathology too, for similar reasons to those motivating expressivism about delusion attribution (although I'd be tempted like Boorse to distinguish disease from illness, where the latter may warrant non-factualism, but the former notion could sensibly be introduced as a factual notion). Then there is a further bifurcation. We should first establish whether the reactive dispositions that underpin our delusion attributions and those that underpin our attributions of illness (or perhaps specifically mental illness) embody norms that are the same, or similar, or completely different. In other words, we need to ask: What is the relationship between our folk-epistemology and our folkpsychiatry, as embodied in our reactive dispositions? The sorts of conditions under which someone (perhaps specifically "a Westerner") might call someone "delusional", "crazy" or "unwell", might well overlap substantially, but not entirely. In short, we might revert to a very close connection between delusion and pathology, but one that looks very different to the presumed factualist orthodoxy. Indeed, we might even revert back to a simple "definition" of delusion as "pathological belief". This is not to be unpacked as a factualist, theoretically-informed, definition, but rather as a way of flagging that our multi-track sensibilities deem belief to be pathological in the simple folk sense that it can't be "understood", is weird, alien, flies in the face of how human beings ought to be, and needs correcting. 


\section{Conclusion}

First I'd like to clarify that my proposal is incomplete in that, although it claims that delusion attribution does not describe and does not function to express factual belief, I have not given a clear positive account of what it does instead, and what it does express. This would have to be left for another day, but I would suggest that it would be consistent with our folkepistemic practices in general, and that these more approximately track social epistemic rather than individual epistemic norms (Miyazono and Salice 2020). As for what is expressed by delusion-talk, my hunch is that this is not going to be something individual like a mental state, but something socially distributed. For want of better terminology, what I have in mind is something like "flagging as suspect", or "enjoining to action". In short, it's about the role it plays in a community, more than the mental state that the individual is in.

Although, theoretically, my central proposal here might seem radical, in practical terms it is not requiring much revision to existing work. Indeed, much of the philosophical work on delusion glosses over strict definitions of delusion, or, at best, provides working or rough definitions, backed up by canonical examples. Then, philosophers focus on the canonical cases themselves asking questions like: "Are they really beliefs?", "What makes them pathological?", "On what grounds might the delusional judgements be made?" What I suggest here has no direct bearing on these questions, for they deal with the phenomena themselves, as already picked out. What I'm talking about here is how the picking out itself seems to work. My suggestion is that, not only is it untidy: it is not even descriptive.

There is, however, some impact of what I'm saying on this work (aside that some may find it interesting). It might be that there is an expectation that delusion could be cleanly defined; it just hasn't been achieved yet. And the take-home message here is that this would be a mistake, and we should rest comfortable in the understanding of the kind of term that "delusion" really is. In a related manner, a lot of philosophical work on delusion lacks clear quantification. You see questions like: "Are delusions beliefs?", "Are delusions irrational?", "What makes delusions pathological?", "Are delusions harmful malfunctioning beliefs?" A logician presented with these questions would ask: All delusions? And if so, is it by definition or contingently the case? My proposal makes explicit what remains largely implicit: that these questions deal with the paradigms, not the parameters, of delusion.

Finally, what I am suggesting here in no way undermines careful psychiatric taxonomy, and diagnostic clinical practice. In fact, it siphons 
off the question of whether something is a delusion or not as something that is not of theoretical relevance. In a modification of G. E. Moore's Open Question Argument (Moore 1903), you can describe any condition in the greatest detail, and someone could still without inconsistency or ignorance ask, "Yes, I understand this condition, but is it delusional?" Establishing delusion-status is not a scientific or theoretical enterprise, and it saves time, energy and confusion to recognise this.

\section{Acknowledgements}

I would like to thank Valentina Petrolini, Emiliano Loria and Marko Jurjako for extremely helpful comments.

\section{REFERENCES}

American Psychiatric Association. 2013. Diagnostic Statistical Manual of Mental Disorders, Fifth edition (DSM-5).

Ayer, A. J. 1952. Language, Truth and Logic. New York: Dover Publications, first Dover edition.

Blackburn, S. 1993. Essays in Quasi-Realism. New York: Oxford University Press.

Boorse, C. 1975. On the distinction between disease and illness. Philosophy and Public Affairs 5: 49-68.

Bortolotti, L. 2009. Delusions and Other Irrational Beliefs. Oxford: Oxford University Press.

Boyer, P. 2001. Religion Explained. New York: Basic Books.

Cardella, V. this issue. Rationality in mental disorders: Too little or too much? European Journal of Analytic Philosophy. https://doi.org/10.31820/ejap.16.2.1

Coltheart, M. 2007. Cognitive neuropsychiatry and delusional belief (The 33rd Sir Frederick Bartlett Lecture). The Quarterly Journal of Experimental Psychology, 60(8): 1041-1062.

David, A. S. 1999. On the impossibility of defining delusions. Philosophy, Psychiatry, and Psychology 6(1):17-20.

Field, H. 1998. Epistemological nonfactualism and the aprioricity of logic. Philosophical Studies 92(1): 1-24.

Gibbard, A. 1990. Wise Choices, Apt Feelings. Cambridge: Harvard University Press.

Hare, R. M., 1952. The Language of Morals, Oxford: Clarendon. https://doi.org/10.1007/s11229-020-02863-1

Jaspers, K, 1963. General Psychopathology. Translated by J. Hoenig and M. Hamilton, Manchester: Manchester University Press. 
Lancellotta, E. and Bortolotti, L. this issue. Delusions in the two-factor theory: Pathological or adaptive? European Journal of Analytic Philosophy. https://doi.org/10.31820/ejap.16.2.2

Langdon, R., and M. Coltheart. 2000. The cognitive neuropsychology of delusions. In Pathologies of Belief, eds. M. Coltheart and M. Davies, 183-216. Oxford: Blackwell.

Mackie, J. L. 1977. Ethics: Inventing Right and Wrong. Harmondsworth: Penguin.

Mele, A. 2006. Self-Deception and delusions. European Journal of Analytic Philosophy 2(1): 109-124. https://hrcak.srce.hr/91611

Miyazono, K. 2015. Delusions as harmful malfunctioning beliefs. Consciousness and Cognition 33: 561-573.

Miyazono, K., and A. Salice. 2020. Social epistemological conception of delusion. Synthese.

Moore, G. E. 1903. Principia Ethica, Cambridge: Cambridge University Press.

Murphy, D. 2012. The folk epistemology of delusions. Neuroethics, 5(1): 19-22.

Murphy, D. 2013. Delusions, modernist epistemology and irrational belief. Mind \& Language, 28(1): 113-124.

Nozick, R. 1993. The Nature of Rationality. Princeton: Princeton University Press.

Petrolini, V. 2017. What makes delusions pathological? Philosophical Psychology 30(4):1-22.

Radden, J. 2010. On Delusion. Abingdon and New York: Routledge.

Ridge, M. 2014. Impassioned Belief. Oxford: Oxford University Press.

Schroeder, M. 2008. Being For. Oxford: Oxford University Press.

Sellars, W. 1957. Counterfactuals, dispositions, and the causal modalities. In Minnesota Studies in the Philosophy of Science, eds. H. Feigl, M. Scriven, and G. Maxwell, 225-308. Minneapolis: University of Minnesota Press.

Velleman, J. D. 2000. The Possibility of Practical Reason. Oxford: Clarendon.

Wakefield, J. C. 1992. The concept of mental disorder: On the boundary between biological facts and social values. American Psychologist 47(3): 373-88.

Wedgwood, R. 2002. The aim of belief. Noûs 36: 267-297.

Williams, B. 1970. Deciding to believe. Language, Belief, and Metaphysics, eds. Howard E. Kiefer and M. K. Munitz, 95-111. Albany: SUNY Press. 
Sam Wilkinson 